Article

\title{
Overall Environmental Equipment Effectiveness as a Metric of a Lean and Green Manufacturing System
}

\section{Rosario Domingo ${ }^{1, *}$ and Sergio Aguado ${ }^{2}$}

1 Department of Manufacturing Engineering, Universidad Nacional de Educación a Distancia (UNED), C/Juan del Rosal 12, Madrid E-28040, Spain

2 Adviser Products Cooking BSH Hausgeräte GmbH, Carl-Wery-Strasse 34, München D-81739, Germany; E-Mail: sergio.aguado@bshg.com

* Author to whom correspondence should be addressed; E-Mail: rdomingo@ind.uned.es; Tel.: +34-913-986-455; Fax: +34-913-986-046.

Academic Editor: Sangkyun Kim

Received: 13 April 2015 / Accepted: 3 July 2015 / Published: 10 July 2015

\begin{abstract}
This paper presents a new metric for describing the sustainability improvements achieved, relative to the company's initial situation, after implementing a lean and green manufacturing system. The final value of this metric is identified as the Overall Environmental Equipment Effectiveness (OEEE), which is used to analyze the evolution between two identified states of the Overall Equipment Effectiveness (OEE) and the sustainability together, and references, globally and individually, the production steps. The OEE is a known measure of equipment utilization, which includes the availability, quality and performance of each production step, In addition to these factors, the OEEE incorporates the concept of sustainability based on the calculated environmental impact of the complete product life cycle. Action research based on the different manufacturing processes of a tube fabrication company is conducted to assess the potential impact of this new indicator. The case study demonstrates the compatibility between green and lean manufacturing, using a common metric. The OEEE allows sustainability to be integrated into business decisions, and compares the environmental impact of two states, by identifying the improvements undertaken within the company's processes.
\end{abstract}

Keywords: sustainability; lean manufacturing; environmental impact; green manufacturing; metric; overall equipment effectiveness 


\section{Introduction}

At present, lean and green practices are being implemented in manufacturing companies in a variety of industries. The elimination of non-value-adding activities is a central tenet of lean manufacturing. It reduces costs and production times, and improves process and product quality, as well as offering other benefits. However, companies also face legal requirements that necessitate a degree of environmentally conscientious practices, leading companies to adopt green practices. As a consequence, many companies have integrated these practices; nonetheless, these companies still require indicators that can provide data to inform decision-making. In fact, Ioppolo et al. [1] observed difficulties in the integration and implantation of these lean and green concepts. In this context, it would be useful to address these challenges by focusing on an indicator that is currently used in lean manufacturing, the Overall Equipment Effectiveness (OEE). This is understood as a measure for representing the effectiveness of equipment utilization in a simple and intuitive way [2]. The relationship between availability, performance and quality established in the OEE is key to its usefulness, and has resulted in its employ as an indicator in businesses' decision-making processes. If we also take a parallel look at the green manufacturing, the analysis is primarily related to environmental impacts. However, standardized indicators have also been developed, such as Ecoindicator-99, which agglomerates all emissions under a single unit millipoint [3]. Nevertheless, the academic literature does not reveal a common indicator that allows the evaluation of all improvements achieved with respect to both lean and green practices. Aguado et al. [4] present a model of efficient and sustainable improvements in a lean production system through processes of environmental innovation, which was successfully applied to a company. However, the results are not related to the OEE and do not also differentiate the improvements obtained due to sustainable outcomes from each workstation of the manufacturing process. This paper is an extension of the work carried out by Aguado et al. [4] but focuses on the identification of the improvements obtained within each manufacturing process of an industrial plant in terms of availability, performance, quality and sustainability, to determine the overall progress achieved by applying lean and green techniques. A new metric based on the OEE, the Overall Environmental Equipment Effectiveness (OEEE), is defined and applied to the action research of Aguado et al. [4].

\section{Literature Review}

This section reviews the existing literature related to the implementation of a lean and green manufacturing system, the benefits and difficulties of achieving the common objectives and the approaches for measuring the progresses on sustainability. In addition, the possibilities for measuring the OEE and the integration of parameters into the OEE are reviewed, and the environmental impact measurement is analyzed.

\subsection{Lean and Green Practices}

The terms "lean" and "green" are well known to most, but a review of both will aid in understanding the proposals put forth by other authors. Lean products can be described as a result of both a philosophy and a set of tools and techniques for identifying and eliminating all waste in 
manufacturing operations [5]. Meanwhile, the term "green" is also used to describe products with the potential to aggregate long-term benefits, reducing consumer stress and ameliorating customer environmental responsibility while maintaining the positive qualities of the product [6]. As a consequence of these two assumptions, lean and green products are reached through a lean and green production. Consumer interest in achieving sustainable development is not new [7,8]. Furthermore, superior product performance is a means of obtaining consumer loyalty for a specific brand and/or product [9], and in this case, declaring a product to be green and lean is relevant to the value the consumer assigns to the product [10].

Pujari et al. [11] attempt to integrate New Product Development (NPD) and environmental management philosophies to develop and empirically test a theoretical method for the development of new environmental products (Environmental New Product Development, ENPD). This study contributes to the discussion of green and competitive possibilities by examining the relationships between the ENPD activities, the market and the eco-performance of new environmental products. The results suggest a synergy between the paradigms of conventional and environmental product development.

The authors note two important considerations. First, consumers today exhibit increasingly rapid changes in taste, shortening product life cycles and, thereby, an increasing importance of NPD for business success. Second, responding adequately to concerns regarding environmental impacts remains a challenge for many enterprises and has become an essential component of corporate strategies.

More recently, Pujari [12] has identified a lack of eco-friendly manufacturing processes and approaches in the existing literature and therefore a need for empirical studies, to explore how to increase the product market success achievement. This work also expounds upon the ENPD process, which is defined as an analysis of life cycle that includes new activities, such as designing for the environment and the participation of suppliers in an environmentally sensitive manner. This approach uses hierarchical regression to identify the related and incremental impacts of the activities of eco-innovation projects for ENPD and their performance in the market. Thus, the factors that influence the market for greener products are considered by the developers of new products, environmental specialists, and suppliers based on the market approach and life cycle analysis.

Bergmiller and McCright [13] investigate factories visited by the Shingo Prize between the years 2000 and 2005 to relate sustainable green practices with lean practices. These authors draw two main conclusions:

(1) Among the visited factories, the lean plants have a better sustainable result than the average.

(2) Further research into the synergy between lean and sustainable systems will offer the greatest potential to improve their effectiveness.

Yang et al. [14] explore the relationship between lean manufacturing practices, environmental management and business performance. The results of this research propose that lean manufacturing experiences are positively related to environmental management practices but also that the implementation of environmental management practices alone has a negative effect on competitiveness in the market and on financial performance. The study provides empirical evidence (based on a large sample) to suggest that environmental management practices are an important tool for resolving conflicts between lean manufacturing and environmental performance. The authors underline two observations derived from their empirical results: 
(1) Lean manufacturing and environmental management practices are different approaches and have different impacts on business performance outcomes.

(2) It is essential that companies understand the consequences of their actions on environmental management, spurred by the existing discussion about their environmental and economic objectives.

In the same way, and continuing the revision of the literature through the years, Azevedo et al. [15] show that lean and green practices improve economic, social, and environmental performance, with the case of a Portuguese automaker used as an example. The authors conclude that, although there are relationships between these practices, future studies must define comprehensive metrics to link all these aspects together.

Gunasekaran and Spalanzani [16] assert that Sustainable Business Development (SBD) in manufacturing and service industries has become a crucial issue in recent years due to increased global awareness among consumers. It is evident that the future quality of the environment is in question, generating great concern for the welfare of future generations. As a result, the authors affirm that the success of a business depends on the preservation of the environment, the safety and well-being of those living today and the safety and well-being of future generations. According to the authors, sustainability is focused on protecting natural resources from exploitation, with the ultimate goal of maintaining or increasing productivity and competitiveness. Thus, the pressure to promote sustainable practices is both external (public policies and nonprofit organizations) and internal (strategic goals, employee safety and satisfaction, cost savings, productivity and quality). The researchers also note that many companies around the world have already incorporated corporate, economic, social and environmental responsibilities into their strategic plans.

Smith and Ball [17] are also of the opinion that a sustainable society cannot be established without more efficient manufacturing approaches and technologies and that these must be provided by the manufacturer. The authors indicate that the available literature covers the principles of green manufacturing but not how to apply these principles. Low-level guidelines are required to evaluate manufacturing facilities, and to make possible the identification and selection of opportunities for improvement. New methodologies should provide detailed guidance on approaches for the systematic analysis of manufacturing processes as well. In their study, the authors created guidelines for defining Material, Energy, and Waste (MEW) flows, and their efforts support the search for green production practices. The proposal presented in their work is based on an installation case and the use of flow maps of qualitative processes. The collected data were used to create a spreadsheet guide, which was then applied to each of the MEW flow processes within the system. Accordingly, this proposal facilitates the identification and selection of practices intended to improve environmental efficiency. The key points identified during the so-called analysis of learning generate a set of guidelines for the analysis of a system. Similarly, to reduce $\mathrm{CO}_{2}$ emissions, Wu et al. [18] propose a methodology, based on lean tools, for the identification of activities that do not add value to the production process.

Dües et al. [19] focus on the relationship between lean and green. Their analysis of the literature identified how lean practices can serve as both a catalyst of and a synergistic approach for achieving green practices. In other words, lean manufacturing is beneficial for green practices, and the implementation of green practices also positively affects current businesses. Moreover, Dües et al. [19] 
also note the difficulty in finding studies that relate lean and green aspects. They indicate that the existing documentation lacks explanations for approaches that can be used to integrate green methodologies into current lean practices.

Diaz-Elsayed et al. [20] discuss the integration of lean and green practices within parts production in the automotive industry, ultimately achieving an important reduction in production costs. Meanwhile, Manzouri et al. [21] find that many companies, especially small enterprises, are unaware of lean tools and their potential to eliminate waste. Thus, Ioppolo et al. [1] propose integrating environmental aspects into lean manufacturing, identifying both opportunities and barriers. The authors report on the current difficultly of locating information on approaches for changing existing production practices from the perspective of the manufacturer. Finally, Pampanelli et al. [22] offer an integrated lean and green approach, providing information about the synergy between lean and green practices. They report that implementing these changes can reduce operational costs by $5 \%-10 \%$ through waste minimization when both principles are applied in a production cell.

These studies develop several interesting points for further consideration.

(1) Synergy exists between the paradigms of conventional and environmental product development and green and lean manufacturing.

(2) The challenge of responding adequately to environmental concerns affects many aspects of enterprises and has become an essential component of corporate strategies. Companies must measure their environmental performance as an indicator of the effect of their environmental impact management practices on other business performance results.

(3) The existing literature lacks empirical studies on approaches for increasing the eco-friendliness of products and their success in the market. The available literature covers the principles of sustainable manufacturing, but there is little to no information on how these principles can be applied. New methodologies should provide detailed guidance on approaches for the systematic analysis of manufacturing practices as well as assistance with the identification and selection of improvement opportunities.

(4) The future of the Earth, and, therefore, the health and well-being of future generations, is of concern. Sustainability is focused on protecting natural resources from exploitation while maintaining productivity and competitiveness. The pressure to promote sustainable practices is both external and internal.

\subsection{Overall Equipment Effectiveness and Environmental Impact}

Since the OEE indicator for measuring the implementation of Total Productive Maintenance (TPM), was defined by Nakajima [23], who also later explained its implementation [24], and it has been included as one of the six techniques used by the lean production [25]. In general, OEE is determined according to each machine used in a production process to identify its availability, quality and performance contributions and to observe the possible relationships between the different parameters of influence, as seen in Borkowski et al. [26]. The OEE has been applied as a measurement tool and decision-making aid for improving productivity by improving equipment [27], and its utility as an indicator in the aerospace industry has been demonstrated [28]. The high potential of OEE has supported its consideration as a basis for analyzing equipment reliability [29]. For these reasons, 
studies have been conducted to analyze the convenience of its adaptation to and incorporation into other indicators. For example, Wudhikarn [30] attempts to improve the OEE to assess equipment losses by normalizing the units of measure as monetary units and thereby considering the quality costs.

Wang and Pan [31] propose the simultaneous use of OEE and unit-per-hour machine rates to obtain complete data for the analysis of equipment processing rates. Oechsner et al. [32] introduce additional parameters into the OEE to find a metric for the entire factory and collect productivity data. Other studies have focused on determining the proper weight of each overall equipment effectiveness element [33]. Another modification of the OEE is focused on the overall throughput effectiveness metric, which cannot be identified as appropriate or inappropriate in general because it depends on the specific product or process [34]. Applications of this indicator can be found in very different industries, including nougat fabrication [35] and intelligent manufacturing systems [36].

As noted, the literature includes attempts to improve the OEE, although amongst these a relationship with sustainability has not been established. Thus, the new parameter presented in this paper, the OEEE, is intended to initiate an open discussion to address the four points identified in Subsection 2.1. The result is highly representative of the existing synergies between lean and green and provides an intuitive and easy means of assessing the progress made at each workstation. The intuitive nature and easiness means of the results lead to one of the goals of this new parameter OEEE, to allow individuals who are not experts in green and lean manufacturing to make appropriate business decisions, taking into account also sustainable facts.

The OEEE depends on initial and final environmental assessments, which can be conducted by any valid method to identify the environmental impact of each step in the process, interconnecting the related environmental aspects [37]. The indicator most commonly used to measure the environmental impact is the equivalent $\mathrm{CO}_{2}$ emission for all greenhouse gas emissions, such as methane and nitrous oxide. Even so, it has previously been shown that the parameters of industrial processes determine not only the outcomes of manufacturing but also the $\mathrm{CO}_{2}$ emissions [38]. Many different methodologies can be used to calculate environmental impact, such as Ecotax [39], Ecovalue08 [40], Ecoindicator-99 [41] and Ecoinvent 3 [42], each of which has unique advantages and disadvantages [43]. A case study carried out by Aguado et al. [4] used Ecoindicator-99 [44], which is also applied in the analysis presented in this paper. Ecoindicator-99 [44] provides a measure of the environmental impact calculated by millipoints [3] at each step in the production line, taking into account the product's entire life cycle.

In this way, the concept of sustainable production in an organization is interpreted appropriately by relying on measurable indicators, which serve to improve the performance of lean and green manufacturing systems.

Before conducting the environmental impact analysis, it is important to set the criteria that will be accepted and applied throughout the process. Any change in these criteria requires a re-evaluation of the initial status to maintain the coherence of the results. If the criteria change and the initial state is not re-evaluated, a degree of confusion related to the final results could arise, reducing the representativeness of the conclusion with respect to actuality. 


\section{Overall Environmental Equipment Effectiveness}

As noted in Subsection 2.2, the new metric Overall Environmental Equipment Effectiveness (OEEE) presented in this paper is based on the OEE [1,23,45] (see Equation (1)).

$$
\text { OEE }=\text { Availability } \times \text { Performance } \times \text { Quality }
$$

The OEEE is the result of perceptual indicators used to represent the capacity of a workstation, taking into account its availability, performance, quality and sustainability. The aim of this new parameter, OEEE, is to identify the losses due to sustainability and establish a complete understanding of the production process in terms of availability, performance, quality and sustainability. The identification and measurement of these inefficiencies will allow the company to implement the necessary corrective actions to improve the production process (see Equation (2)).

$$
\text { OEEE }=\text { OEE } \times \text { Sustainability }
$$

Availability refers to the amount of real time in which a work unit is operational and actively producing material, beginning with the set-up time of the post [28]. This term takes into account the time lost due to machine adjustments, configuration of the workstation, and other unexpected breaks in production. The planned time for production does not include the organized stops and non-working times, such as workers' pauses during production.

Performance takes into account the unrecorded downtime, comparing the real against the theoretical quantity of produced parts, which should have been produced during the ideal cycle time [28]. The ideal cycle time is the minimum period of production time expected in optimal circumstances of work. Performance includes speed losses due to small stops and other issues. If a takt time, which is the time needed to obtain a part according to the market requirements [45], is defined, then this value will be taken as the ideal cycle time.

The quality rate captures the time lost due to the rejection of parts during production and the losses from the time between initial start-up to process stabilization [28]. Quality refers to the good pieces produced as a proportion of the total pieces produced.

In addition to these three terms, which are already included in the OEE, a new factor related to sustainability is added to the equation to represent the environmental efficiency of the workstation (see Equation (3)).

$$
\text { Sustainability }=1-\frac{\text { Environmental impact of the workstation state }}{\text { Total environmental impact of initial state production }}
$$

Note that in Equation (3), the environmental impact of the workstation state is referred to the moment of analysis: initial or final. The environmental impact can be measured using any method, some of them already identified in Subsection 2.2. The only requirement is that the correct unit demanded by each method be used at this step. In this case study, the millipoint was chosen, but any other unit of environmental impact could have been used, as, for example, the equivalent $\mathrm{CO}_{2}$. The fact of identifying the relevant parameter (unit measure) for each company or production process is another advantage of this new tool. Once this unit has been chosen, it must be kept during the whole process, in order to maintain the coherence of the results between the initial and final status. 
The Sustainability parameter is always referred to the total environmental impact measured at the initial status, so this is the first value to calculate. Once this value is identified, it is compared to the value of each workstation. It means that we are comparing the environmental impact state of each workstation against the total initial environmental impact state. This approach provides two interesting advantages:

- When compared the final state, the improvement achieved by each workstation is provided, referred to the initial state.

- When compared the initial or final state, the worst workstation, in which improvements would be most beneficial, can be easily identified, because it has the worst value of Sustainability.

However, the relationship between this factor and the initial number of environmental impact could create confusion because the definition of this parameter will never allow $100 \%$ effectiveness at all the workstations. This fact is important when defining the optimal ranges that can be achieved by the OEEE. Besides, the complementarity of the previous result, between the environmental impact of each workstation and the total environmental impact of the initial state, is needed to retain the effectiveness criteria used in the other parameters already included in the OEE.

Joint analysis of availability, performance, quality and sustainability provides a fast and easy-to-understand representation of the OEEE of a functional workstation. A more in-depth analysis can reveal which of the four parameters should be improved to increase the capacity of the functional unit. The introduction of a new OEEE metric for each workstation will allow the optimal decisions to be made in terms of availability, performance, quality and sustainability. It could be considered that the competitiveness begins within the company between the different functional units.

Hansen [46] classifies the OEE degrees of optimization. This paper suggests the following OEEE categories, taking into account the effect of sustainability on the ranges defined by Hansen. The objective of surpassing $85 \%$, gives excellent competitive functionality. Values between $85 \%$ and $70 \%$ are considered good, while those from $70 \%$ to $60 \%$ are considered only acceptable, indicating a manufacturing process with slight economic losses and low competitiveness. A value of $60 \%$ should be considered the minimum allowable for a functional unit in a company that wants to stay in the market in the long run. Table 1 presents the ranges for the different OEEE measures. Due to a lack of contrast with the sustainability parameter, the proposed OEEE scale requires a more exhaustive analysis to achieve a contrasting perspective, which is reserved for future study.

Table 1. Interpretation of the ranges for Overall Environmental Equipment Effectiveness (OEEE) measures.

\begin{tabular}{ccc}
\hline OEEE & Result & Status \\
\hline OEEE $<60 \%$ & Bad & Low competitiveness \\
$60 \%<$ OEEE $<70 \%$ & Acceptable & \\
$70 \%<$ OEEE $<85 \%$ & Good & \\
$85 \%<$ OEEE & Excellent & High competitiveness \\
\hline
\end{tabular}

The OEEE parameter challenges companies to quantify improvements to availability, performance, quality and sustainability achieved after improving the initial state. The objective of the OEEE is to show where losses occur, checking and understanding the value OEEE of each workstation. These 
losses may result from problems with availability (unexpected stops), performance (bottlenecks), quality (defects or scraps) and/or sustainability (millipoints). This metric can inform decisions intended to correct or improve each situation.

Finally, the OEEE aims to chase "waste" produced by millipoints stops, faults, preparation of machines, loss of productivity and rejections together, using a single working tool. Considering all of the aforementioned points, the OEEE is a promising approach for improving the synergy between a lean and green manufacturing system based on sustainability.

\section{Methodology}

To demonstrate the advantages of the OEEE, an action-based research approach has been developed. Since Lewin [47] established the concept of action research, this methodology has been used in the academic literature, including in studies related to the environment [48]. In action research, the researcher must be present and participates in the organization's development and implementation of process modifications and improvements [49].

The new parameter OEEE proposed is aimed at companies in the secondary sector with flexible manufacturing processes depending on the demand and harmonized distribution of resources along the production line. As a result, for the primary and tertiary sectors some adjustments should be included. In addition, some corrections related to the size of the company could be needed.

The measures required in the availability, performance and quality calculations were collected using a structured questionnaire administered through interviews at a tube manufacturing plant, at which the researcher analyzed the measures and helped to implement the actions recommended by the conclusions.

This kind of audit was focused on four main aspects: green contribution, social responsibility, economical development and public policies. Each one of these aspects is divided into six different fields: social necessities, material supply, manufacturing, distribution, product and waste. On this way, the complete structure of the organization is analyzed, included all the production steps following a "pull" direction, from the desire of the customer to the entry of raw materials.

In this particular study, the material analyzed is galvanized steel. This material is altered during the manufacturing process; the initial galvanized steel has a zinc coating of $275 \mathrm{~g} / \mathrm{mm}^{2}$ (DX53D $+\mathrm{Z} 275$ ), while the final material has a zinc coating of $120 \mathrm{~g} / \mathrm{mm}^{2}(\mathrm{DX} 51 \mathrm{D}+\mathrm{Z} 120)$. Note that the designation of the material is according to the standard EN 10346 [50].

The environmental impact has been determined using the method Ecoindicator-99 [44] through the whole life cycle of the product. SimaPro software was utilized [51] to get the millipoints values of each workstation.

\section{Results and Discussion}

Aguado et al. [4] present a case study based on a tube fabrication company, where a model of efficient and sustainable improvements in a lean production system is implemented through processes of environmental innovation. The Ecoindicator-99 [44] metric was used in the aforementioned study and will also be used in the analysis in this paper to identify the effect of sustainability, as measured in millipoints. The use of the same metric will guarantee that the same criteria are maintained, allowing meaningful comparison. 
The following criteria should also be considered:

- One single reference part represents all of the producible parts.

- Only the reference part is produced.

- Each machine can only be adjusted a pre-defined number of times per day depending on the parts requested.

- The analysis includes the millipoints due to the re-utility or recovery of raw material.

- The takt time is used to define the performance of the final state.

In the case study of the tube fabrication company, nine steps are identified at the initial status of the analysis, each of which has its own millipoints account. Applying the model proposed by Aguado et al. [4], eight steps remain, as the control and labeling is done in a single workstation, instead of using two different working steps. Table 2 presents the environmental impact, in millipoints $(\mathrm{mPt})$, of the initial and final states of this case study of a tube fabrication company.

Table 2. Environmental impact.

\begin{tabular}{ccc}
\hline Production Process & Initial Environmental Impact (mPt) & Final Environmental Impact (mPt) \\
\hline Reception & 103.4737 & 56.3370 \\
Cutting & 16.6578 & 0.033 \\
Closing & 0.0001 & 0.001 \\
Welding & 6.8732 & 6.8732 \\
Punching & 0.0073 & 0.0073 \\
Bending & 1.7530 & 1.7530 \\
Control & 0.0001 & 0.0001 \\
Labeling & 0.0001 & 16.015 \\
Shipping & 16.015 & 81.02 \\
TOTAL & 144.78 & \\
\hline
\end{tabular}

The data from the initial situation related to the factors of the OEEE are presented in Table 3.

Table 3. Initial sustainability, availability, performance and quality results.

\begin{tabular}{|c|c|c|c|c|c|c|c|c|c|}
\hline nitial $\quad$ Process & Receiving & Cutting & Closing & Welding & Punching & Bending & Control & Labeling & Shipping \\
\hline Sustainability (\%) & 28.53 & 88.49 & 100.00 & 95.25 & 99.99 & 98.79 & 100.00 & 100.00 & 88.94 \\
\hline Availability (\%) & 16.13 & 41.71 & 99.95 & 97.55 & 93.61 & 89.41 & 69.63 & 50.71 & 63.64 \\
\hline Performance (\%) & 66.67 & 84.21 & 97.90 & 89.89 & 88.89 & 93.02 & 95.52 & 94.12 & 25.00 \\
\hline Quality (\%) & 100.00 & 99.43 & 99.82 & 94.89 & 99.86 & 99.86 & 95.69 & 100.00 & 100.00 \\
\hline
\end{tabular}

The data for the final state, where control and labeling have been unified, are shown in Table 4. 
Table 4. Final sustainability, availability, performance and quality results.

\begin{tabular}{lcccccccc}
\hline Final & Process & Receiving & Cutting & Closing Welding & Punching & Bending & $\begin{array}{c}\text { Control } \\
\text { Labeling }\end{array}$ & Shipping \\
\hline Sustainability (\%) & 61.09 & 99.98 & 100.00 & 95.25 & 99.99 & 98.79 & 100.00 & 88.94 \\
Availability (\%) & 5.46 & 73.13 & 85.31 & 90.63 & 90.52 & 72.34 & 90.34 & 72.76 \\
Performance (\%) & 100.00 & 100.00 & 100.00 & 100.00 & 100.00 & 100.00 & 100.00 & 100.00 \\
Quality (\%) & 100.00 & 99.27 & 99.86 & 99.88 & 99.90 & 99.90 & 99.19 & 100.00 \\
\hline
\end{tabular}

Raw material is only received two days per week in the initial state, whereas it is received daily in the final state. The two situations are not easily compared because the same criteria are not used. Therefore, the analysis can proceed in one of two possible ways:

(a) The two processes can be analyzed independently, as shown in the figures above, by conducting the analysis for one of the two days per week on which materials are delivered in the initial state.

(b) The initial state can be distributed over five days. This approach will be used hereafter.

According to these results, a significant improvement is obtained between the initial and final states after implementing the model for efficient and sustainable improvements in a lean production system according to processes of environmental innovation. A step-by-step comparison reveals the improvements to each term. Figures 1 and 2 correspond to the OEE and OEEE, respectively and according to the values of the Tables 3 and 4 (see Equations (1) and (2)). Remarks, as previously explained, thanks to the improvements made, the control and labeling processes are done in the same workstation at the final state.

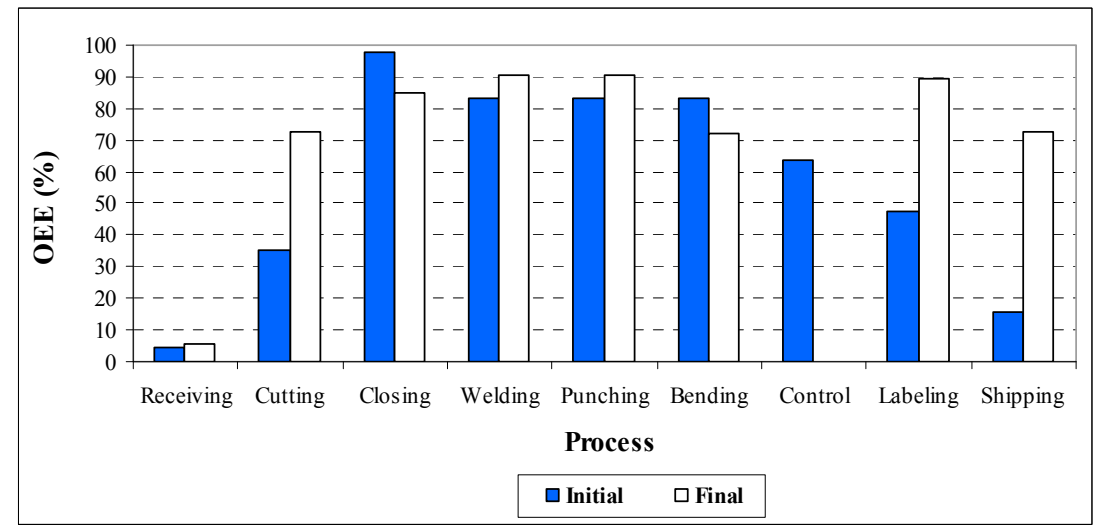

Figure 1. OEE of each production process.

Figures 1 and 2 look similar, but Figure 2 includes extra information related to the sustainability factor, as shown in Tables 3 and 4. This detailed sustainability information helps identify the greatest opportunities for environmental improvements. It is evident that the next decision should be to improve the material receiving step of the process, which is the only workstation under acceptable $60 \%$ OEEE, even if the sustainability value of this step has been improved. This improvement can only be identified if the OEEE is correctly analyzed. 


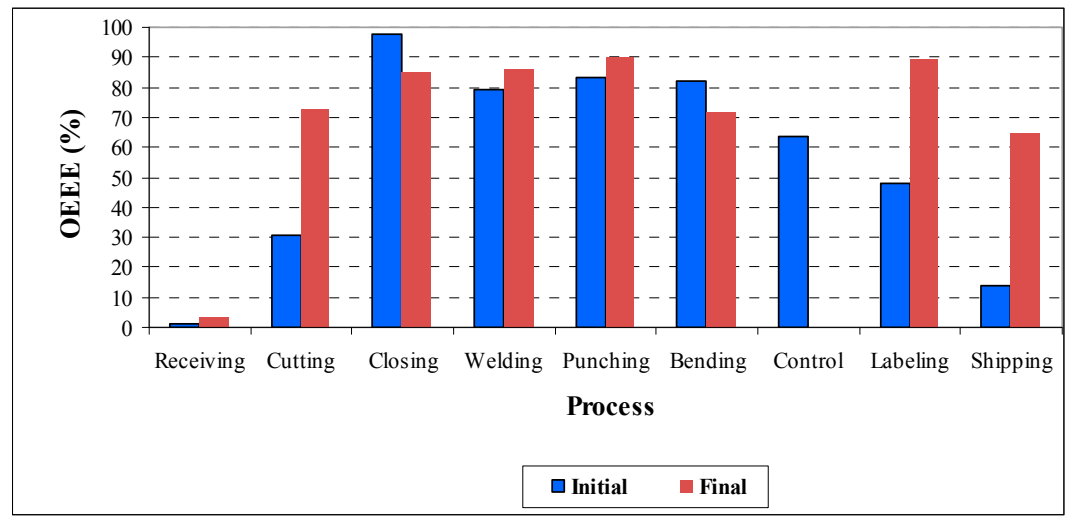

Figure 2. OEEE of each production process.

Changes in product development were begun at the point of material receiving. The sustainability indicator for receiving is improved from $28.53 \%$ to $61.09 \%$; this finding is in concordance with the Ecoindicator-99 result, which decreased from 144.78 millipoints to 81.02 millipoints. This result was obtained by changing the raw material (from DX53D + Z275 to DX51D + Z120), which a deeper analysis identified as more beneficial and for which a lower market price could be established. The decision to change the raw material was motivated by the improvement in sustainability. The environmental impact of the new material is lower than the original one. As a consequence of this, the value of millipoints in the final Receiving workstation is lower than in its initial state, and the final result of the Sustainability parameter of the Receiving workstation improves. This change was the starting point for all other modifications to the production line. A lean adaptation was required according to the takt time, and a focus on the customer was key for the company's success. This sentiment was integrated inside the company by considering the subsequent production step as the customer of the previous step and was integrated outside the company with the suppliers, who adopted just-in-time delivery (e.g., the delivery of tubes five times per week instead of two).

The consequences of the synergies between green and lean can be pointed out in the Figures 1 and 2 , where the columns of the final state are more harmonized. It means that there are no big gaps between workstations. Initially, the closing was higher than $90 \%$, but four other workstations were under $50 \%$. At the final state, excepting the receiving workstation, all the others have values between $57 \%$ and 91\%. Comparing the results OEE and OEEE, these ones are a little bit lower, so the initial suggestion to classify the OEEE ranges based on the OEE could be accepted till further researches. The stockpiles between workstations disappeared or were greatly reduced; the production batches decreased; new investments allowed for quick adjustments to the machines; and the layout was defined according to the production needs. All of the modifications were implemented based on the information obtained from the OEEE, thanks to change the raw material of the tube. Here, the sustainability analysis was the starting point for all the improvements undertaken.

In terms of business results, each of these improvements had a positive effect. The removal of stockpiles eliminated unnecessary materials and prevented money from being tied up inside the factory (between workstations and in the incoming and shipping warehouses). Small batches and quick adjustments provide the flexibility to respond to the customers' requirements (the time needed for the 
first part produced was reduced from 2.301 to $685 \mathrm{~s}$ ), and the overall production process runs smoothly (no bottlenecks or quality breaks).

Finally, the costs for each step of production in the initial and final states are compared in Table 5. The final cost of the reference product is $6.2 \%$ cheaper.

Table 5. Costs in the initial and final states.

\begin{tabular}{ccc}
\hline Production Process & Initial Cost (€/unit) & Final Cost (€/unit) \\
\hline Reception & 0.010 & 0.010 \\
Cutting & 0.134 & 0.243 \\
Closing & 0.401 & 0.286 \\
Welding & 0.312 & 0.303 \\
Punching & 0.315 & 0.304 \\
Bending & 0.301 & 0.243 \\
Control & 0.235 & 0.304 \\
Labeling & 0.179 & 0.182 \\
Shipping & 0.112 & 1.875 \\
TOTAL & 1.999 &
\end{tabular}

As a consequence of the internal progress made, the final product is more competitive in terms of price, flexibility and sustainability while maintaining the quality required by the customer [4]. This is a step toward securing customer loyalty. Although the improvement processes in the case study are not yet finished, new efforts to improve the final state are being defined based on these results.

\section{Conclusions}

The Overall Environmental Equipment Effectiveness (OEEE) metric is presented in this paper as a possible solution to the four questions identified regarding green and lean manufacturing. A case study is used to assess this metric, and the following conclusions are drawn.

(1) The OEEE is a new parameter that allows companies to include sustainability in business decisions.

(2) The OEEE demonstrates the compatibility between green and lean manufacturing.

(3) The OEEE provides a new methodology for integrating sustainability practices into business decisions.

(4) The OEEE compares the environmental impact of two states, identifying the improvements that have been made.

The authors' intention is to initiate a discussion of this new OEEE parameter and its contribution to the existing literature as a methodology allowing companies to include sustainability as a criterion in business decision-making. 


\section{Acknowledgments}

The authors thank the Industrial Production and Manufacturing Engineering (IPME) research group, the Spanish Ministry of Economy and Competitiveness (project DPI2011-27135) and the Industrial Engineering School, UNED, (project REF2014-ICF07) for their support. The authors also thank the three anonymous reviewers for their valuable and constructive comments on earlier versions of the paper.

\section{Author Contributions}

All authors contributed equally to this work. All authors have read and approved the final manuscript.

\section{Conflicts of Interest}

The authors declare no conflict of interest.

\section{References}

1. Ioppolo, G.; Cucurachi, S.; Salomone, R.; Saija, G.; Ciraolo, L. Industrial ecology and environmental lean management: Lights and shadows. Sustainability 2014, 6, 6362-6376.

2. Singh, R.; Shah, D.B.; Gohil, A.M.; Shah, M.H. Overall equipment effectiveness (OEE) calculation-Automation through hardware \& software development. Procedia Eng. 2013, 51, 579-584.

3. Goedkoop, M.; Spriensma, R. The Eco-indicator '99. A Damage-Oriented Method for Life Cycle Impact Assessment; Pré Consultants: Amersfort, The Netherlands, 1999.

4. Aguado, S.; Alvarez, R.; Domingo, R. Model of efficient and sustainable improvements in a lean production system through processes of environmental innovation. J. Clean Prod. 2013, 47, 141-148.

5. Powell, D.; Strandhagen, J.O.; Tommelein, I.; Ballard, G.; Rossi, M. A new set of principles for pursuing the lean ideal in engineer to order manufacturers. Procedia CIRP 2014, 17, 571-576.

6. De Medeiros, J.F.; Duarte Ribeiro, J.L.; Nogueira Cortimiglia, M. Success factors for environmentally sustainable product innovation: A systematic literature review. J. Clean Prod. 2014, 65, 76-86.

7. Porter, M.E.; van de Linde, C. Toward a new conception of the environment-competitiveness relationship. J. Econ. Perspect. 1995, 9, 97-118.

8. Porter, M.E.; van de Linde, C. Green and competitive: Breaking the stale-mate. Harv. Bus. Rev. 1995, 73, 120-134.

9. Gupta, S.; Kumar, V. Sustainability as corporate culture of a brand for superior performance. J. World Bus. 2013, 48, 311-320.

10. Butz, H.E.; Goodstein, L.D. Measuring customer value: Gaining the strategic advantage. Organ. Dyn. 1996, 24, 63-77.

11. Pujari, D.; Wright, G.; Peattiec, K. Green and competitive influences on environmental new product development performance. J. Bus. Res. 2003, 56, 657-671.

12. Pujari, D. Eco-innovation and new product development: Understanding the influences on market performance. Technovation 2006, 26, 76-85. 
13. Bergmiller, G.; McCright, P. Lean manufacturers' transcendence to green manufacturing. In Proceedings of the 2009 Industrial Engineering Research Conference, Miami, FL, USA, 30 May-3 June 2009.

14. Yang, M.; Hong, P.; Modi, S. Impact of lean manufacturing and environmental management on business performance: An empirical study of manufacturing firms. Int. J. Prod. Econ. 2011, 129, 251-261.

15. Azevedo, S.G.; Carvalho, H.; Duarte, S.; Cruz-Machado, V. Influence of green and lean upstream supply chain management practices on business sustainability. IEEE Trans. Eng. Manag. 2012, 59, 753-765.

16. Gunasekaran, A.; Spalanzani, A. Sustainability of manufacturing and services: Investigations for research and applications. Int. J. Prod. Econ. 2012, 140, 35-47.

17. Smith, L.; Ball, P. Steps towards sustainable manufacturing through modeling material, energy and waste flows. Int. J. Prod. Econ. 2012, 140, 227-238.

18. Wu, P.; Low, S.P.; Jin, X. Identification of non-value adding (NVA) activities in precast concrete installation sites to achieve low-carbon installation. Resour. Conserv. Recycl. 2013, 81, 60-70.

19. Dües, C.; Tan, K.; Lim, M. Green as the new lean: How to use Lean practices as a catalyst to greening your supply chain. J. Clean Prod. 2013, 40, 93-100.

20. Diaz-Elsayed, N.; Jondral, A.; Greinacher, S.; Dornfeld, D.; Lanza, G. Assessment of lean and green strategies by simulation of manufacturing systems in discrete production environments. CIRP Ann-Manuf. Technol. 2013, 62, 475-478.

21. Manzouri, M.; Ab-Rahman, M.N.; Che Mohd Zain, C.R.; Jamsari, E.Z. Increasing production and eliminating waste through lean tools and techniques for halal food companies. Sustainability 2014, 6, 9179-9204.

22. Pampanelli, A.B.; Found, P.; Moura Bernardes, A.M. A lean \& green model for a production cell. J. Clean Prod. 2014, 85, 19-30.

23. Nakajima, S. Introduction to TPM Total Productive Maintenance; Massachusetts Productivity Press: Cambridge, MA, USA, 1988.

24. Nakajima, S. TPM Development Program: Implementing Total Productive Maintenance; Massachusetts Productivity Press: Cambridge, MA, USA, 1989.

25. Galgano, A. Las tres Revoluciones. Caza del Desperdicio: Doblar la Productividad con la "Lean Production” (The Three Revolutions. Hunt Waste: Double Productivity with Lean Production); Ediciones Diaz de Santos: Madrid, Spain, 2004.

26. Borkowski, S.; Czajkowska, A.; Stasiak-Betlejewska, R.; Borade, A.B. Application of TPM indicators for analyzing work time of machines used in the pressure die casting. J. Ind. Eng. Int. 2014, 10, 1-9.

27. Muchiri, P.; Pintelon, L. Performance measurement using overall equipment effectiveness (OEE): Literature review and practical application discussion. Int. J. Prod. Res. 2008, 46, 3517-3535.

28. Puvanasvaran, A.P.; Mei, C.Z.; Alagendran, V.A. Overall equipment efficiency improvement using time study in an aerospace industry. Procedia Eng. 2013, 68, 271-277.

29. Kuo, Y.; Lin, K.P. Using neural network and decision tree for machine reliability prediction. Int. J. Adv. Manuf. Technol. 2010, 50, 1243-1251. 
30. Wudhikarn, R. Improving overall equipment cost loss adding cost of quality. Int. J. Prod. Res. 2012, 50, 3434-3449.

31. Wang, T.Y.; Pan, H.C. Improving the OEE and UPH data quality by Automated Data Collection for the semiconductor assembly industry. Expert Syst. Appl. 2011, 38, 5764-5773.

32. Oechsner, R.; Pfeffer, M.; Pfitzner, L.; Binder, H.; Müller, E.; Vonderstrass, T. From overall equipment efficiency (OEE) to overall Fab effectiveness (OFE). Mater. Sci. Semicond. Process. 2003, 5, 333-339.

33. Yuniawan, D.; Ito, T.; Bin, M.E. Calculation of overall equipment effectiveness weight by Taguchi method with simulation. Concurr. Eng.-Res. Appl. 2013, 21, 296-306.

34. Muthiah, K.M.N.; Huang, S.H.; Mahadevan, S. Automating factory performance diagnostics using overall throughput effectiveness (OTE) metric. Int. J. Adv. Manuf. Technol. 2008, 36, 811-824.

35. Tanco, M.; Santos, J.; Rodríguez, J.L.; Reich, J. Applying lean techniques to nougat fabrication: A seasonal case study. Int. J. Adv. Manuf. Technol. 2013, 68, 1639-1654.

36. Unver, H.O. An ISA-95-based manufacturing intelligence system in support of lean initiatives. Int. J. Adv. Manuf. Technol. 2013, 65, 853-866.

37. Noteboom, S. Impact assessment procedures for sustainable development: A complexity theory perspective. Environ. Impact Assess. Rev. 2007, 27, 645-665.

38. Calvo, L.M.; Domingo, R. Influence of process operating parameters on $\mathrm{CO}_{2}$ emissions in continuous industrial plants. J. Clean Prod. 2015, 96, 253-262.

39. Finnveden, G.; Eldh, P.; Johansson, J. Weighting in LCA based on ecotaxes-Development of a mid-point method and experiences from case studies. Int. J. Life Cycle Assess. 2006, 11, 81-88.

40. Ahlroth, S.; Finnveden, G. Ecovalue08-A new valuation set for environmental systems analysis tool. J. Clean Prod. 2011, 19, 1994-2003.

41. Goedkoop, M.; Oele, M.; Schryver, A.; Vieira, M.; Hegger, S. SimaPro Database Manual. Methods library; PRé Consultants: Amersfoort, The Netherlands, 2010.

42. Weidema, B.P.; Bauer, C.; Hischier, R.; Mutel, C.; Nemecek, T.; Reinhard, J.; Vadenbo, C.O.; Wernet, G. Overview and Methodology. Data Quality Guideline for the Ecoinvent Database Version 3; The Ecoinvent Centre: St. Gallen, Switzerland, 2013.

43. Hertin, J.; Jacob, K.; Pesch, U.; Pacchi, C. The production and use of knowledge in regulatory impact assessment - An empirical analysis. For. Policy Econ. 2009, 11, 413-421.

44. IHOBE. Manual Práctico de Eco-Diseño. Operativa de Implantación en 7 pasos (Practical Handbook of Eco-Design. Operational Implementation in 7 Steps); IHOBE Sociedad Pública de Gestión Ambiental: Bilbao, Spain, 2000.

45. Hansen, R.C. Overall Equipment Effectiveness: A Powerful Production/Maintenance Tool for Increased Profits; Industrial Press Inc.: New York, NY, USA, 2001.

46. Womack, J.P.; Jones, D.T. Lean Thinking: Banish Waste and Create Wealth in Your Corporation; Free Press: New York, NY, USA, 2003.

47. Lewin, K. Action research and minority problems. J. Soc. Issues 1946, 2, 34-46.

48. Farrelly, T.; Tucker, C. Action research and residential waste minimisation in Palmerston North, New Zealand. Resour. Conserv. Recycl. 2014, 91, 11-26. 
49. McNiff, J.; Whitehead, J. Action Research: Principles and Practice, 2nd ed.; Routledge Falmer: New York, NY, USA, 2002.

50. European Committee for Standardization. EN 10346: Continuously Hot-Dip Coated Steel Flat Products-Technical Delivery Conditions; European Committee for Standardization (CEN): Brussels, Belgium, 2009.

51. Pré-Consultants. SimaPro 7.2.3 Software. Available online: http://www.pre-sustainability.com/ faq/where-can-i-download-simapro-7.2.3 (accessed on 16 February 2015).

(C) 2015 by the authors; licensee MDPI, Basel, Switzerland. This article is an open access article distributed under the terms and conditions of the Creative Commons Attribution license (http://creativecommons.org/licenses/by/4.0/). 